\title{
Surgical management of intraocular lens dislocations
}

\section{Tratamento cirúrgico dos deslocamentos de lentes intraoculares}

\author{
Adem Gul ${ }^{1}$, Mustafa Duran ${ }^{1}$, Ertugrul Can $^{1}$, Ozlem Eski Yucel ${ }^{1}$, Yuksel Sullu ${ }^{1}$
}

\begin{abstract}
Purpose: To report and compare the surgical, visual, and anatomical outcomes following treatment of dislocated intraocular lenses (IOLs).

Methods: The medical records of 28 eyes of 28 patients were evaluated. Age, gender, pre-and postoperative best-corrected visual acuity (BCVA), surgical methods, and complications were recorded.

Results: Pre-and postoperative BCVA ranged from counting fingers to 20/32 and from counting fingers to $20 / 25$, respectively. Late-onset dislocations were the most frequently observed complication. The most frequent surgical method was IOL repositioning in 15 of 28 patients, followed by IOL exchange in 11 patients, and $\mathrm{IOL}$ removal in 2 patients. Only 1 patient required surgical re-intervention with IOL capture.

Conclusions: Visual acuity improved following the use of either $\mathrm{OL}$ repositioning or IOL exchange. No superiority of one method over the other was observed. In the present retrospective case series, management of dislocated IOLs with repositioning or exchange of the primary implant conferred comparable surgical and visual outcomes.
\end{abstract}

Keywords: Lens implantation; Intraocular/methods; Lenses intraocular; Visual acuity/ physiology

\section{RESUMO}

Objetivo: Relatar e comparar as abordagens cirúrgicas e os resultados visuais e anatômicos no tratamento de lentes intraoculares (IOL) deslocadas.

Métodos: Foram avaliados os registros médicos de 28 olhos de 28 pacientes. Idade, sexo, melhor acuidade visual corrigida pré e pós-operatória, abordagens cirúrgicas e complicações foram registrados.

Resultados: Melhor acuidade visual corrigida pré e pós-operatória variou de conta dedos a 20/32 e de conta dedos a 20/25, respectivamente. Os deslocamentos tardios foram os mais frequentemente encontrados. A cirurgia mais frequente foi o reposicionamento da $10 \mathrm{~L}$ em 15 dos 28 pacientes, em seguida, o troca da $10 \mathrm{~L}$ em 11 pacientes, e a remoção da $1 O \mathrm{~L}$ em dois pacientes. Apenas um caso de necessitou de reintervenção devido à captura da IOL.

Conclusões: A acuidadevisual melhorou em ambas as abordagens, reposicionamento e troca de IOL. Não houve superioridade de um método sobre o outro. Na presente série de casos retrospectiva, o tratamento do deslocamento de $10 \mathrm{~L}$ com reposição ou troca do implante primário gerou resultados cirúrgicos e visuais comparáveis.

Descritores: Implante de lente intraocular/métodos; Lentes intraoculares; Acuidade visual/fisiologia

\section{INTRODUCTION}

Cataract surgery has been widely and successfully performed with the implantation of posterior chamber intraocular lenses (IOLs). This approach is associated with intra- and postoperative complications, including posterior capsular tears, vitreous loss, and IOL issues. Posterior chamber $\mathrm{IOL}(\mathrm{PCIOL})$ dislocation, the commonest indication for $\mathrm{OL}$ replacement, may lead to visual disturbances such as glare, diplopia, and decreased vision ${ }^{(1)}$.

The most frequent causes of $\mathrm{OL}$ dislocations following cataract surgery are abnormalities in the zonular fibers, insufficient capsular support, and asymmetrical sulcus placement of PCIOL haptics during the original cataract surgery ${ }^{(2)}$. The reported predisposing factors include advanced age, trauma, pseudoexfoliation, uveitis, high myopia, previously vitrectomized eye, and retinitis pigmentosa ${ }^{(3)}$.

Surgical intervention is not essential in all cases of dislocated IOLs. IOL repositioning or exchange may decrease the density of corneal endothelial cells. Further, surgery may not be required in patients who are poor surgical candidates or have good visual function in the opposite eye $\mathrm{e}^{(4)}$. In cases where the dislocated IOL does not cause visual impairment, observation alone may be a viable option. Surgery is mostly indicated in cases of decreased vision, glaucoma, IOL dislo- cation into the vitreous cavity, cystoid macular edema, and retinal detachment.

Surgical options for dislocated IOLs include repositioning, replacement, re-localization to the ciliary sulcus, suturing to the scleral wall, suturing to the iris, and explantation of the $\mathrm{IOL}^{(5-8)}$.

Currently, there is a lack of reports regarding treatment outcomes following IOL dislocation. As IOL dislocations have an extremely low reported incidence rate (between 0.05\% and 0.2\%)(9,10), the present study aimed to report the outcomes following the management of dislocated IOLs in a large number of cases at a tertiary eye clinic.

\section{METHODS}

We retrospectively analyzed the medical records of 28 patients who underwent surgery for dislocated $\mathrm{IOL}$ at a tertiary referral hospital between 2008 and 2012. The present study adhered to the Declaration of Helsinki and was approved by the local ethics committee. The primary outcome measures were predisposing factors, preoperative and postoperative best-corrected visual acuity (BCVA), duration between initial surgery and dislocation, dislocated IOL position, and surgical techniques.
Submitted for publication: May 6, 2015

Accepted for publication: July 11,2015

Ophthalmology Department, Ondokuz Mayis University, Samsun, Turkey.
Funding: No specific financial support was available for this study.

Disclosure of potential conflicts of interest: None of the authors have any potential conflict of interest to disclose.

Corresponding author: Adem Gul. OMU Tip Fakultesi, Atakum, 55000, Samsun - Turkey E-mail: drademgul@gmail.com 
Surgical methods included IOL repositioning, IOL explantation, and $\mathrm{IOL}$ exchange. Surgeries were performed by 4 experienced surgeons.

IOL repositioning without suturing was performed in patients in whom IOL capture was present, and capsular support was adequate for repositioning only.

IOL repositioning with scleral fixation of one or both haptic(s) was performed using needles with a looped 10-0 polypropylene suture (PC-9, Alcon). Knots were tied in a cow hitch. Sutures were tied, and suture ends were left long under the Tenon's fascia. Conjunctiva were closed with 8/0 absorbable sutures (Figure 1, Figure 2).

For IOL explantation, corneal incisions were made between the 10 and 2 o'clock positions. Anterior vitrectomy was performed in the presence of vitreous humor with the aid of triamsinolon acetate.
For IOL exchange, a limbal approach was used. Sclerotomy was not performed in any of the IOL removal procedures in the present study. All new IOLs were implanted at the time of initial surgery.

New IOLs were implanted into the ciliary sulcus or in the bag. In patients with insufficient capsular support, the scleral fixation method was preferred and was performed using standardized surgical procedures without the creation of scleral flaps. The suture ends were left long under Tenon's layer. In the present study, all newly implanted IOLs were placed posterior to the iris. No anterior chamber IOLs (ACIOLs) were used.

Pars plana vitrectomy was performed in cases of IOL dislocation into the vitreous cavity. Standard incisions were made in the sclera, and 23 gauge trocars were placed prior to core vitrectomy (Dorc, Holland). IOLs were manipulated into the anterior chamber using
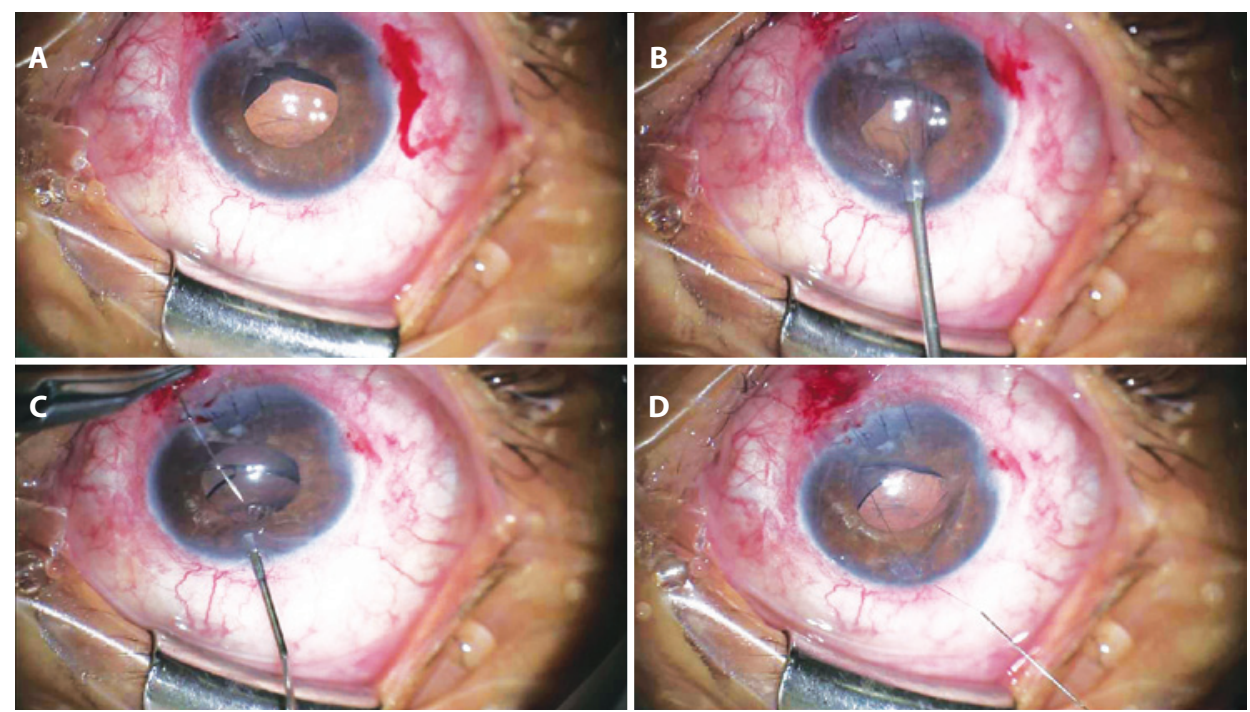

Figure 1. A) Inferiorly dislocated intraocular lens; B) Paracentesis opposite to entrance site; C) Needle passed inferiorly to the haptic; and D) Needle removal following paracentesis.
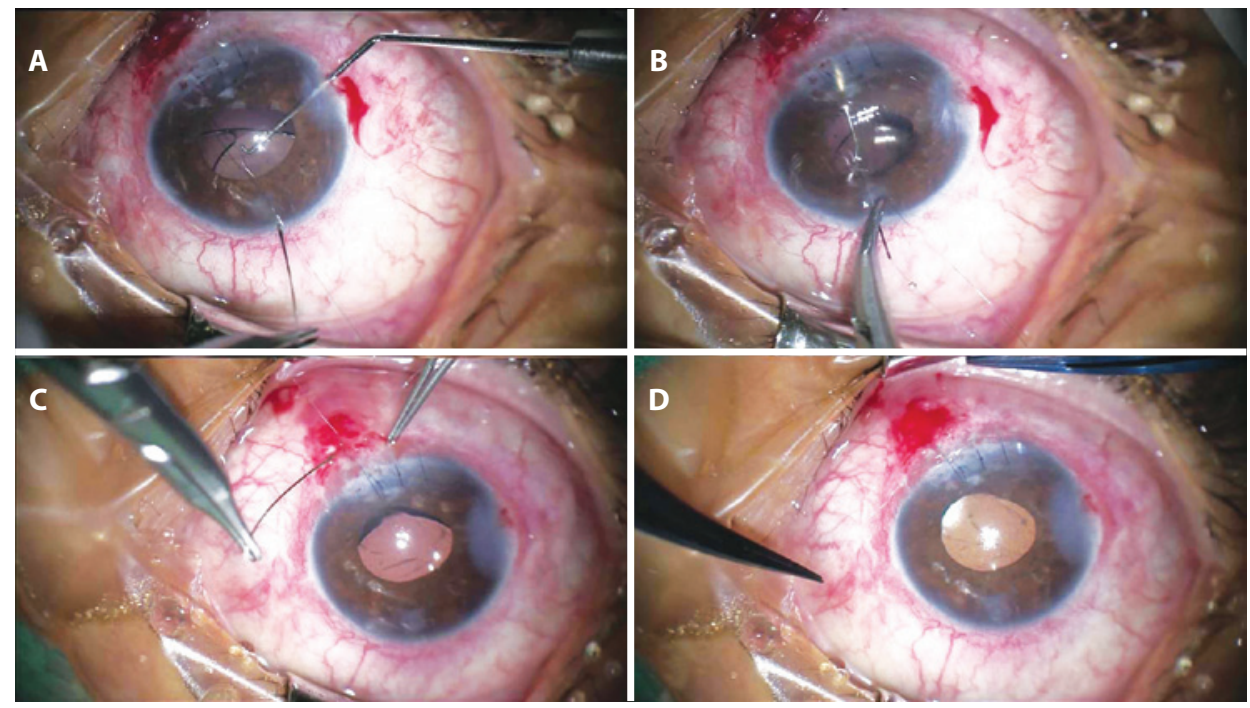

Figure 2. A) Needle re-introduced into the anterior chamber through 2 suture threads to form a knot; B) Needle passed superior to the haptic; C) Introduction of the needle into the sclera with a lamellar approach to tie suture ends (without scleral flap formation); and D) Postoperative centralization of the intraocular lens. 
microforceps under the security of perfluorodecalin to preserve the retina. IOLs were then removed through previously created corneal incisions. Anterior chambers were filled with viscoelastic material to preserve the endothelial surface. The scleral fixation method was performed in all exchange cases of $\mathrm{IOL}$ dislocation into the vitreous cavity.

\section{RESULTS}

The mean age of included patients was 55.6 years (range: 6-86 years). Of the 28 included patients, 15 were male (53.5\%) and 13 were female (46.5\%). The average follow-up duration was 13.3 months (range: $3-42$ months). Surgery was performed on the right eye in 12 patients and the left eye in 16 patients. Three patients had a history of trauma, and the remaining 25 patients had spontaneous IOL dislocation.

All eyes were unilaterally involved. The mean time from cataract surgery to IOL dislocation was 38.1 months (range: 1-10 years).

Preoperative BCVA values ranged from counting fingers to 20/32 and postoperative BCVA ranged from counting fingers to 20/25. The mean postoperative best-corrected vision significantly differed from mean preoperative vision $(P<0.05)$. The final visual acuity was $\geq 20 / 40$ in 13 eyes (46.4\%), between 20/50 and 20/200 in 7 eyes (25\%), and $\leq 20 / 200$ in 8 eyes (28.6\%). With the exception of 1 patient, all patients had stable or improved vision at the end of the follow-up period.

Predisposing factors included pseudoexfoliation in 12 patients (42.8\%), posterior capsular rupture during original cataract surgery in 6 patients (21.4\%), trauma in 3 patients (10.7\%), high myopia in 2 patients $(7.1 \%)$, and no identifiable cause in 5 patients (17.8\%). When the most frequent predisposing causes (pseudo-exfoliation and posterior capsular rupture) were compared, no statistical difference in visual outcomes was observed between the 2 groups.

IOL positions were inferior dislocation in 13 eyes, superior dislocation in 1 eye, temporal dislocation in 1 eye, IOL dislocation into the vitreous cavity in 8 eyes, and captured IOL in 5 eyes. Of the 28 patients, 23 patients were referred from outside ophthalmologists and 5 patients had previously undergone surgery at our department.

Early dislocation (in the first 3 months after initial cataract surgery) was observed in 10 patients, and late dislocation was observed in 16 patients. Precise data regarding surgery times were not available for 2 patients. If the 3 cases of trauma-related IOL dislocation occurring within the first 3 months of surgery were excluded, early dislocations were found to have occurred in 7 patients.

The most frequent surgical procedure was $\mathrm{OL}$ repositioning in 15 of 28 patients. Other surgical procedures included IOL removal in 2 patients and IOL exchange in 11 patients. Details of all surgical procedures are shown in table 1.

IOL repositioning without scleral sutures was performed in 8 cases comprising 4 cases with IOLs implanted into the ciliary sulcus and 4 cases with IOLs implanted in the bag at initial surgery. Captured IOLs were detected in all sulcus-placed IOLs $(n=4)$ upon initial examination. In 2 patients, IOL repositioning with pars plana vitrectomy was performed due to crystalline lens fragments within the vitreous cavity. In 5 patients with IOL dislocation into the vitreous cavity, pars plana vitrectomy followed by the implantation of new $\mathrm{IOL}$ with scleral fixation was performed.

IOL explantation with anterior vitrectomy was performed in 2 patients. New IOLs were not implanted during surgery due to corneal edema, with patients left aphakic.

All IOL exchanges ( $n=13$ ) were performed using the limbal approach.

Re-dislocation occurred in 1 patient who had undergone surgery for IOL capture after the 1 year follow-up period. The patient underwent IOL repositioning without fixation to the sclera or iris. No evidence of re-dislocation was noted at a follow-up visit 16 months later.

\section{DISCUSSION}

IOL dislocations can be categorized into 2 groups according to timing after surgery as early or late dislocations. Early dislocations are defined as dislocation within first 3 months of initial cataract surgery, although early dislocation is mostly observed during the first week postoperatively ${ }^{(2,11,12)}$. The most common cause of early dislocation is reported as zonular rupture, followed by advancing age, trauma, and pseudoexfoliation ${ }^{(11,13)}$. In the present study, 10 of 28 patients $(35.7 \%)$ were admitted during the early period. Three patients had a history of trauma; 2 patients were admitted 1 month after trauma and the other patient was admitted 2 months after trauma. In the remaining 7 patients, predisposing factors included posterior capsular rupture in 5 patients, pseudoexfoliation in 1 patient, and no identifiable cause in 1 patient. In a previous study, IOL dislocations were found to be frequently associated with prior vitrectomy ${ }^{(14)}$. In the present study, posterior capsular rupture during the original cataract surgery occurred in 5 patients. As initial cataract surgery was not performed at our clinic in the majority of patients included in the present study, the present study was limited by a lack of previous intraoperative data including zonular insufficiency, the usage of capsular tension rings, or performance of vitrectomy.

Surgical methods used to the present to correct dislocated IOLS included repositioning with or without fixation to the iris or scleral wall, explantation, and IOL exchange through posterior, anterior, or combined approaches. In previous studies, particularly surgical techniques are frequently preferred over others. Michaeli et al. demonstrated iris fixation as an effective method of repairing lens subluxation in 44 patients ${ }^{(15)}$. Mello et al. performed IOL repositioning in $84.5 \%$, IOL exchange in $14.5 \%$, and IOL removal in $1 \%$ of patients ${ }^{(5)}$. Kim et al. predominantly performed IOL fixation to the scleral wall (39\%), followed by repositioning in 38\%, IOL exchange in 17\%, and IOL removal in $2 \%$ of patients ${ }^{(6)}$. Gross et al. performed a study involving in-the-bag PCIOL dislocation in 25 eyes and reported replacement of an $\mathrm{ACIOL}$ as the most frequent intervention in $60 \%$ of cases, followed by repositioning/exchanging and scleral fixation in the remaining $40 \%$ of eyes ${ }^{(11)}$. Jakobsson et al. studied 91 eyes and reported the use of IOL repositioning with scleral suturing in $94 \%$ of eyes ${ }^{(9)}$. In the present study, the most frequently used surgical technique was IOL repositioning in 15 of 28 patients (54\%), comparable to the previous studies of Mello(5) and Jakobsson ${ }^{(9)}$. Repositioning does not require IOL removal or the creation of corneal incisions. Accordingly, this approach results in minimal damage to the corneal endothelial surface. Scleral suturing of one or both haptic(s) was performed in 5 of $15 \mathrm{IOL}$ repositioning cases in the present study.

Suturing of the haptics to the sclera may result in suture erosion, suture breakage, IOL redislocation, vitreous hemorrhage, or retinal detachment. In the present study, no suture-related complications were observed over an average follow-up time of 13.3 months.

$\mathrm{IOL}$ repositioning or exchange are effective surgical methods for correcting dislocated IOLs remains controversial. Ostern et al. reported no significant difference in outcomes between exchange surgery and scleral fixation ${ }^{(10)}$. Sarrafizadeh et al. reported similar final visual outcomes between eyes that underwent IOL repositioning and eyes that underwent IOL exchange with implantation of an ACIOL. This study also demonstrated a higher rate of postoperative IOL subluxation following the use of $\mathrm{OL}$ repositioning compared to IOL exchange $(21 \% \text { vs } 3 \%)^{(8)}$. Steinmetz et al. reported outcomes following PCIOL removal and ACIOL implantation. In this study, suprachoroidal hemorrhage occurred in 2 eyes, retinal detachment in 5 eyes, and cystoid macular edema in 13 eyes ${ }^{(16)}$. Zheng et al. exchanged all dislocated out-of-the-bag IOLs with new PCIOLs and observed no significant improvement in BCVA ${ }^{(17)}$. Anterior chamber or scleral fixated IOLs (SFIOLS) are most commonly used in IOL exchange. Serif et al. and Burcu et al. exchanged the majority of IOLs with SFIOLs $s^{(18,19)}$. Sturmer exchanged dislocated IOLs with ACIOLs and reported that 
Table 1. Patient details

\begin{tabular}{|c|c|c|c|c|c|c|c|c|c|}
\hline Patient & $\begin{array}{c}\text { Age } \\
\text { (years) }\end{array}$ & Gender & Side & Duration (m) & $\begin{array}{c}\text { Predisposing } \\
\text { factors }\end{array}$ & $\begin{array}{c}\text { Preoperative visual } \\
\text { acuity }\end{array}$ & $\begin{array}{l}\text { Postoperative } \\
\text { visual acuity }\end{array}$ & Dislocation type & Intervention \\
\hline 1 & 76 & M & R & 4 & PEX & $20 / 50$ & $20 / 25$ & IOL capture & IOL repositioning \\
\hline 2 & 6 & $\mathrm{~F}$ & L & 0.25 & & $\leq 20 / 200$ & $20 / 100$ & IOL capture & IOL repositioning* \\
\hline 3 & 73 & M & $R$ & 120 & Trauma & $20 / 32$ & $20 / 25$ & Inferior & IOL repositioning \\
\hline 4 & 32 & M & L & 120 & & $20 / 50$ & $20 / 25$ & IOL capture & IOL repositioning \\
\hline 5 & 71 & M & L & 3 & PEX & $\leq 20 / 200$ & $\leq 20 / 200$ & Inferior & IOL repositioning \\
\hline 6 & 60 & M & L & 4 & & $\leq 20 / 200$ & $20 / 63$ & IOL capture & IOL repositioning \\
\hline 7 & 28 & M & R & 96 & Trauma & $\leq 20 / 200$ & $\leq 20 / 200$ & IOL capture & $\begin{array}{c}\text { IOL repositioning } \\
\text { (one haptic SF) }\end{array}$ \\
\hline 8 & 84 & M & L & 25 & PEX & $20 / 63$ & $20 / 40$ & Inferior & $\begin{array}{l}\text { IOL repositioning } \\
\text { (one haptic SF) }\end{array}$ \\
\hline 9 & 80 & M & R & 0.25 & PCR & $\leq 20 / 200$ & $20 / 63$ & Inferior & $\begin{array}{c}\text { IOL repositioning } \\
\text { (one haptic SF) }\end{array}$ \\
\hline 10 & 47 & M & L & 4 & Trauma & $\leq 20 / 200$ & $20 / 100$ & Inferior & $\begin{array}{c}\text { IOL repositioning } \\
\text { (one haptic SF) }\end{array}$ \\
\hline 11 & 40 & $\mathrm{~F}$ & $\mathrm{R}$ & 0.5 & PCR & $\leq 20 / 200$ & $20 / 40$ & Inferior & $\begin{array}{c}\text { IOL repositioning } \\
\text { (one haptic SF) }\end{array}$ \\
\hline 12 & 67 & M & L & 8 & PEX & $20 / 63$ & $20 / 25$ & Inferior & $\begin{array}{c}\text { IOL repositioning } \\
+\mathrm{AV}\end{array}$ \\
\hline 13 & 32 & $\mathrm{~F}$ & L & & & $20 / 50$ & $20 / 25$ & Inferior & $\begin{array}{l}\text { IOL repositioning } \\
+\mathrm{AV}\end{array}$ \\
\hline 14 & 60 & M & L & 1 & PCR & $\leq 20 / 200$ & $\leq 20 / 200$ & In vitreous & $\begin{array}{l}\text { IOL repositioning } \\
\quad+\text { PPV }\end{array}$ \\
\hline 15 & 69 & M & R & 1 & PEX & $20 / 50$ & $20 / 40$ & In vitreous & $\begin{array}{c}\text { IOL repositioning } \\
\quad+\mathrm{PPV}\end{array}$ \\
\hline 16 & 48 & M & L & 3 & PEX & $\leq 20 / 200$ & $20 / 100$ & Temporal & IOL exchange \\
\hline 17 & 61 & $\mathrm{~F}$ & R & 0.5 & PEX & $\leq 20 / 200$ & $\leq 20 / 200$ & Inferior & $\begin{array}{l}\text { IOL exchange } \\
\text { (sulcus) }\end{array}$ \\
\hline 18 & 15 & $\mathrm{~F}$ & $R$ & 96 & High myopia & $20 / 100$ & $20 / 50$ & Inferior & $\begin{array}{l}\text { IOL exchange } \\
\text { (sulcus) }\end{array}$ \\
\hline 19 & 70 & M & L & 0.5 & PEX & $\leq 20 / 200$ & $20 / 32$ & In vitreous & $\begin{array}{l}\text { IOL exchange } \\
\text { (sulcus) + PPV }\end{array}$ \\
\hline 20 & 78 & $\mathrm{~F}$ & $R$ & 0.25 & PEX & $\leq 20 / 200$ & $20 / 40$ & In vitreous & $\begin{array}{l}\text { IOL exchange } \\
\text { (sulcus) + PPV }\end{array}$ \\
\hline 21 & 68 & $\mathrm{~F}$ & L & 12 & PEX & $20 / 100$ & $20 / 40$ & Inferior & IOL exchange (SF) \\
\hline 22 & 19 & $\mathrm{~F}$ & R & 120 & & $\leq 20 / 200$ & $20 / 32$ & Superior & $\begin{array}{c}\text { IOL exchange (SF) } \\
+ \text { AV }\end{array}$ \\
\hline 23 & 34 & $\mathrm{~F}$ & L & 12 & High myopia & $\leq 20 / 200$ & $\leq 20 / 200$ & In vitreous & $\begin{array}{c}\text { IOL exchange (SF) } \\
+ \text { PPV }\end{array}$ \\
\hline 24 & 65 & $\mathrm{~F}$ & R & 0.5 & PEX & $\leq 20 / 200$ & $\leq 20 / 200$ & In vitreous & $\begin{array}{c}\text { IOL exchange (SF) } \\
+ \text { PPV }\end{array}$ \\
\hline 25 & 58 & M & L & 1 & $P C R$ & $20 / 32$ & $20 / 32$ & In vitreous & $\begin{array}{c}\text { IOL exchange (SF) } \\
+ \text { PPV }\end{array}$ \\
\hline 26 & 80 & $\mathrm{~F}$ & L & 2 & $P C R$ & $\leq 20 / 200$ & $20 / 63$ & In vitreous & $\begin{array}{c}\text { IOL exchange (SF) } \\
+ \text { PPV }\end{array}$ \\
\hline 27 & 52 & $\mathrm{~F}$ & L & 0.25 & PCR & $\leq 20 / 200$ & $\leq 20 / 200$ & Inferior & IOL explantation \\
\hline 28 & 86 & $\mathrm{~F}$ & $\mathrm{R}$ & & PEX & $\leq 20 / 200$ & $\leq 20 / 200$ & Inferior & $\begin{array}{c}\text { IOL explantation } \\
+\mathrm{AV}\end{array}$ \\
\hline
\end{tabular}

$\mathrm{AV}=$ anterior vitrectomy; $\mathrm{F}=$ female; $\mathrm{L}=$ left; $\mathrm{IOL}=$ intraocular lens; $\mathrm{M}=$ male; $\mathrm{m}=$ month; $\mathrm{PCR}=$ posterior capsular rupture; $\mathrm{PEX}=\mathrm{pseudo-exfoliation;} \mathrm{PPV}=$ pars plana vitrectomy; $\mathrm{R}=$ right; $\mathrm{SF}=$ scleral fixation; ${ }^{*}=$ cases requiring re-intervention.

postoperative intraocular pressure decompensation and vascular problems as major complications ${ }^{(20)}$. Ostern et al. demonstrated the use of anterior chamber or PMMA iris claw lenses either posterior or anterior to the iris ${ }^{(10)}$. In the present study, ACIOLs were not used. All new IOLs were implanted posterior to the iris to protect corneal endothelial function from the deleterious effects of multiple surgeries.
IOL removal is generally performed via limbal or pars plana approaches. Steinmetz et al. demonstrated the safe exchange of posteriorly dislocated IOLs with ACIOLs using the pars plana approach ${ }^{(16)}$ The limbal approach is associated with a number of risks including endothelial damage, trauma to the iris, hyphema, and corneal astigmatism. In the present study, surgery using the limbal approach was 
performed in 13 of 28 eyes. In cases of IOL dislocation into the vitreous cavity, the use of microforceps for grasping and stabilizing the $I O L$ with the aid of perfluorodecalin was found to be a very effective method. Perfluorodecalin was used in 5 of 28 patients in the present study, all of whom had IOL dislocation into the vitreous cavity, with no complications such as retinal tears or retinal edema ${ }^{(21)}$ observed.

Complications associated with IOL dislocation include glaucoma and posterior segment pathologies. In a previous study, posterior segment pathology (retinal detachment) as a complication of treatment of IOL dislocation was reported in $10 \%$ of cases $^{(8)}$. In another study, cystoid macular edema was reported as a complication in 22\% of cases of IOL dislocation ${ }^{(16)}$. Re-dislocation is reportedly infrequent, as in the present study where only 1 case of re-dislocation was observed following repositioning surgery. Although cystoid macular edema is reportedly the commonest complication of IOL dislocation management $t^{(5,6)}$, no significant intra- or postoperative complications were observed in the present study, except a single case of secondary glaucoma in a patient who underwent IOL exchange, possibly due to residual cortical material. Lim et al. reported secondary glaucoma may occur up to several years after cataract surgery ${ }^{(22)}$.

The most frequently conducted IOL dislocation surgeries in the present study can be categorized into the following 2 groups: repositioning $(n=15)$ and exchange $(n=11)$. Indeed, the average postoperative visual acuity increased compared to preoperative values with the use of both approaches. No statistical differences in final visual outcomes were observed between the 2 groups.

This was a retrospective study on the outcomes following IOL dislocation management in 28 patients. Although the most preferred surgical method was found to be IOL repositioning in the present study, clinicians tended to choose different surgical approaches depending on the severity of $\mathrm{OL}$ dislocation. While repositioning was preferred in cases of minor dislocation, complete IOL removal was considered in particularly severe cases.

In the present retrospective case series, the management of dislocated IOLs with repositioning or exchange of the primary implant provided comparable surgical and visual outcomes.

\section{REFERENCES}

1. Jones JJ, Jones YJ, Jin GJ. Indications and outcomes of intraocular lens exchange during a recent 5-year period. Am J Ophthalmol. 2014;157(1):154-62.

2. Gimbel HV, Condon GP, Kohnen T, Olson RJ, Halkiadakisl. Late in-the-bag intraocular lens dislocation: incidence, prevention, and management. J Cataract Refract Surg. 2005;31:2193-204.

3. Hayashi K, Hirata A, Hayashi H. Possible predisposing factors for in-the-bag and out-of-the-bag intraocular lens dislocation and outcomes of intraocular lens exchange surgery. Ophthalmology. 2007;114(5):969-1975.

4. Wang Y, Wu M, Zhu L, Liu Y. Long-term corneal endothelial cell changes in pediatric intraocular lens reposition and exchange cases. Graefes Arch Clin Exp Ophthalmol. 2012;250(4):547-55.

5. Mello MO Jr, Scott IU, Smiddy WE, Flynn HW, Feuer W. Surgical management and outcomes of dislocated intraocular lenses. Ophthalmology. 2000;107(1):62-7.

6. Kim SS, Smiddy WE, Feuer W, Shi W. Management of dislocated intraocular lenses. Ophthalmology. 2008;115(10):1699-704.

7. Chan CK, Agarwal A. Management of dislocated intraocular implants. Ophthalmol Clin North Am. 2001;14(4):681-93.

8. Sarrafizadeh R, Ruby AJ, Hassan TS, Williams GA, Garretson BR, Trese MT, et al. A comparison of visual results and complications in eyes with posterior chamber intraocular lens dislocation treated with pars plana vitrectomy and lens repositioning or lens exchange. Ophthalmology. 2001;108(1):82-9.

9. Jakobsson G, Zetterberg M, Sundelin K, Stenevi U. Surgical repositioning of intraocular lenses after late dislocation: complications, effect on intraocular pressure, and visual outcomes. J Cataract Refract Surg. 2013;39(12):1879-85.

10. Ostern AE, Sandvik GF, Drolsum L. Late in-the-bag intraocular lens dislocation in eyes with pseudoexfoliation syndrome. Acta Ophthalmol. 2014;92(2):184-91.

11. Gross JG, Kokame GT, Weinberg DV. Dislocated In-The-Bag Intraocular Lens Study Group. In-the-bag intraocular lens dislocation. Am J Ophthalmol. 2004;137(4):630-5.

12. Coelho RP, Zanatto MC, Paula JS, Romão E. Spontaneous late in-the-bag intraocular lens dislocation after can-opener capsulotomy: case report. Arq Bras Oftalmol. 2005; 68(6):864-6.

13. Zech JC, Tanniere P, Trepsat C. Posterior chamber intraocular lens dislocation with the bag. J Cataract Refract Surg. 1999;25(8):1168-9.

14. Matsumoto M, Yamada K, Uematsu M, Fujikawa A, Tsuiki E, Kumagami T, et al. Spontaneous dislocation of in-the-bag intraocular lens primarily in cases with prior vitrectomy. Eur J Ophthalmol. 2012;22(3):363-7

15. Michaeli A, Soiberman U, Loewenstein A. Outcome of iris fixation of subluxated intraocular lenses. Graefes Arch Clin Exp Ophthalmol. 2012;250(9):1327-32.

16. Steinmetz RL, Brooks HL Jr, Newell CK. Management of posteriorly dislocated posterior chamber intraocular lenses by vitrectomy and pars plana removal. Retina. 2004; 24:556-9.

17. Zheng DY, Chen LN, Sun Y, Shao YF, Liang JL, Liu YZ, et al. Out-of-the-bag intraocular lens dislocation: outcomes of posterior chamber intraocular lens exchange, risk factors, and prevention. Chin Med J (Engl). 2010;123(18):2562-7.

18. Serif N, Ozdek S, Gurelik G, Akata F, Hasanreisoglu B. Surgical treatment modalities and outcomes of dislocated IOLs into the vitreus. Ret-Vit. 2006;14(3):181-4.

19. Burcu A, Yalniz-Akkaya Z, Abay I, Acar MA, Ornek F. Scleral-fixated posterior chamber intraocular lens implantation in pediatric and adult patients. Semin Ophthalmol. 2014; 29(1):39-44.

20. Stürmer J. [Lens exchange for subluxation of posterior chamber lenses implanted in the capsular bag or in the ciliary sulcus]. Klin Monbl Augenheilkd. 2013;230(4):317-22. German.

21. Mensiz E, Aytuluner E, Ozerturk Y. Scleral fixation suture technique without lens removal for posteriorly dislocated intraocular lenses. Can J Ophthalmol. 2002;37(5):290-4.

22. Lim MC, Doe EA, Vroman DT, Rosa RH Jr, Parrish RK $2^{\text {nd }}$. Late onset lens particle glaucoma as a consequence of spontaneous dislocation of an intraocular lens in pseudoexfoliation syndrome. Am J Ophthalmol. 2001;132(2):261-3. 